\title{
Development of New Anticoagulants: Present and Future
}

\author{
Job Harenberg, M.D. ${ }^{1}$
}

\section{ABSTRACT}

Anticoagulant drugs are the most frequently hospital-prescribed compounds in many countries and are used with the intention to prevent and treat venous and arterial thromboembolism. Because of side effects and the necessity of dose adjustment of unfractionated heparins and coumarins, low-molecular-weight heparins, heparinoids, and direct systemically applied thrombin inhibitors were developed. Because of limitations of these anticoagulants, synthetic indirect and direct factor $\mathrm{Xa}$ inhibitors and direct thrombin inhibitors were further developed with the aim to improve the benefit/risk ratio for anticoagulant therapy of patients using a simplified mode of action. This overview describes the results of some recent studies of these inhibitors of blood coagulation.

KEYWORDS: Thromboembolism, heparin, low-molecular-weight heparin, factor Xa inhibitors, direct thrombin inhibitors, rivaroxaban, apixaban, idraparinux, ximelagatran, dabigatran

The treatment of thromboembolic diseases is one of the main therapeutic areas in medicine, because up to $50 \%$ of patients with acute deep vein thrombosis (DVT) will die without anticoagulant treatment within a few days. Heparin historically reduced the mortality rate to less than 5\%. Unfractionated heparin (UFH) became the drug of choice in the mid-20th century for this indication. Because of the necessity of laboratory monitoring by the activated partial thromboplastin time, which had to be prolonged 2 to 3 times the normal value, low-molecular-weight heparins (LMWHs) have been developed.

Eberhard Mammen identified in the mid-20th century the inhibition of coagulation factor 3 through anticoagulants such as heparin. ${ }^{1}$ Soon thereafter, he described the benefit of anticoagulation of blood in hemodialysis patients with heparin. ${ }^{2}$ At the beginning of the LMWH era, he investigated the pharmacody- namics of LMWH. ${ }^{3}$ He identified the reduced incidence of heparin-induced thrombocytopenia as one of the main advantages over conventional heparins. He wrote in 1990:

"the introduction of LMW heparins has opened new avenues for the management of patients with thromboembolic diseases. In contrast to regular heparin, the mean molecular weights are smaller and represent about half that of regular heparin. Yet, they are still somewhat heterogeneous and seem to differ from preparation to preparation in some of their biologic properties. No two LMW heparins are alike. In spite of these differences, certain commonalities do exist, which may represent an advantage over unfractionated heparin, especially in their use as a prophylactic antithrombotic modality: 1 . LMWHs are at least as effective, if not more effective, as antithrombotic agents when com-
${ }^{1}$ Clinical Pharmacology, Faculty of Medicine Mannheim, RuprechtKarls University of Heidelberg, Mannheim, Germany.

Address for correspondence and reprint requests: Job Harenberg, M.D., Clinical Pharmacology, Faculty of Medicine Mannheim, Ruprecht-Karls University of Heidelberg, Theodor Kutzer Ufer 1-3, D-68167 Mannheim, Germany (e-mail: job.harenberg@medma. uni-heidelberg.de).
A Tribute to Eberhard F. Mammen, M.D. (1930-2008); Guest Editor, Emmanuel J. Favaloro, Ph.D., M.A.I.M.S.

Semin Thromb Hemost 2008;34:779-793. Copyright (C) 2008 by Thieme Medical Publishers, Inc., 333 Seventh Avenue, New York, NY 10001, USA. Tel: $+1(212)$ 584-4662.

DOI 10.1055/s-0029-1145260. ISSN 0094-6176. 
pared with unfractionated heparin. 2. The rate of absorption from the subcutaneous depots is more complete, leading to a longer efficacy in vivo. This translates to a once a day injection instead of the twice a day use of unfractionated heparin. 3. There are suggestions that their use is associated with less bleeding than unfractionated heparin, although the final outcome awaits completion of many ongoing clinical trials. LMW heparins are not free of bleeding complications, but hemorrhages seem to occur that are dose dependent. 4. The overall incidence of heparin-induced thrombocytopenia seems to be markedly reduced with LMW heparins. It is still encountered in an occasional patient and may be related to the preparation used. There is reason to believe that heparin fractions free of heparin-induced thrombocytopenia will be forthcoming. As LMW heparins are used therapeutically, new dosage schemes and new laboratory tests will have to be developed to assure maximum safety for the patients". 4
Later he focused on the relevance to differentiate LMWHs. 5

He participated in 2002 in one of the Glycosaminoglycan Symposia held in the Villa Vigoni at Menaggio situated at Lake Como in northern Italy (Figs. 1 and 2). He invited the organizers of the symposia to submit manuscripts of the participants for publication in Seminars in Thrombosis and Hemostasis on the occasions of the 3rd, 10th, and 14th Glycosaminoglycan Symposia, each of these symposia having selected manuscripts published 1 year later in $1994,{ }^{6} 2002,{ }^{7}$ and $2007 .{ }^{8}$

In the preface of the 2002 volume of Seminars in Thrombosis and Hemostasis, he described the anticoagulant and non-anticoagulant actions of glycosaminoglycans (GAGs) as topics of the 8th symposium. The most widely known GAGs are heparins and LMWHs and they are best known for their anticoagulant properties. Although the clinical usefulness of heparins cannot be disputed, there are serious side effects associated with their use,

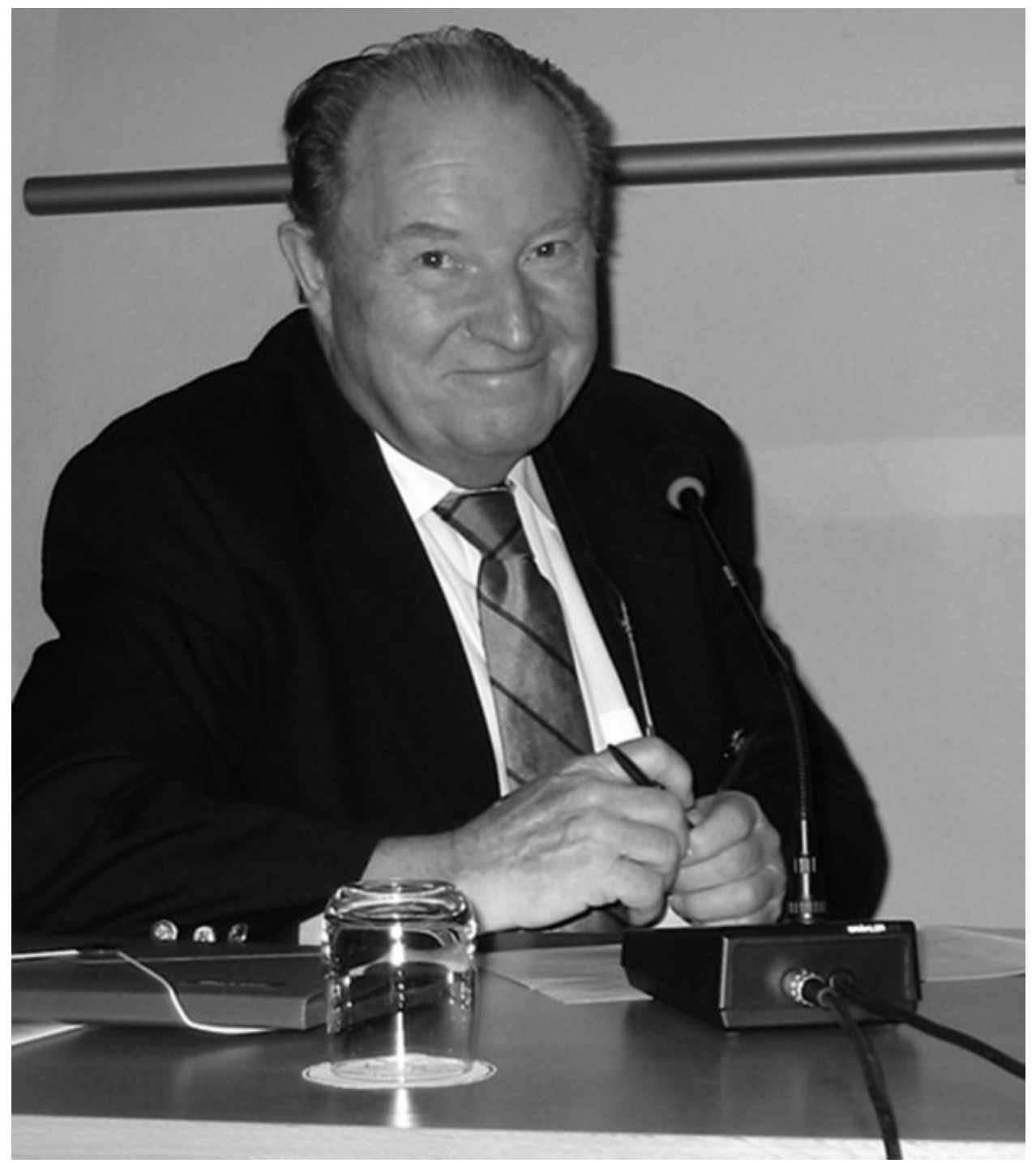

Figure 1 Eberhard Mammen at the 10th Glycosaminoglycan Symposium, September 20, 2002. 


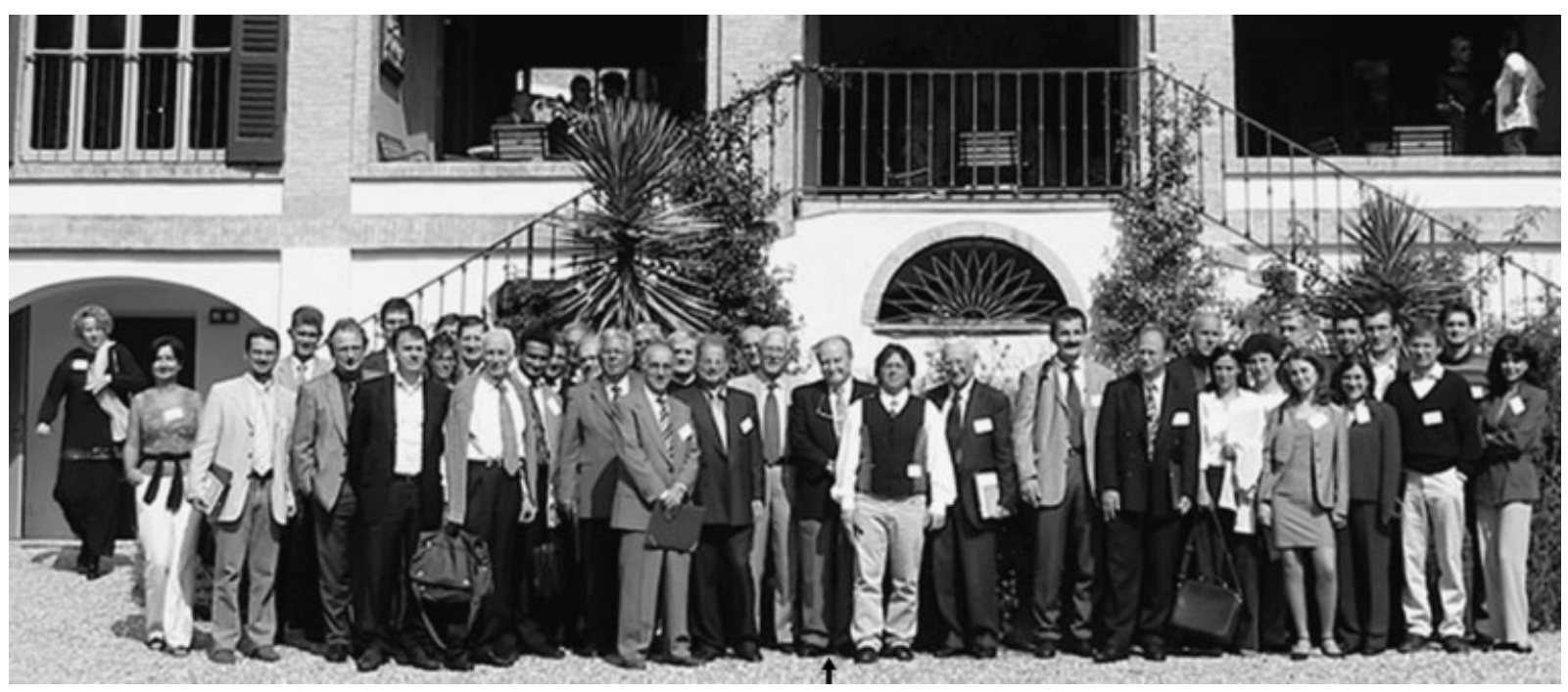

Figure 2 Eberhard Mammen (indicated by an arrow) in the group of participants of the 10th Glycosaminoglycan Symposium, September 20th, 2002.

more with UFH than with LMWH. These problems have spurred continuous efforts to develop modifications of UFH to make compounds safer without compromising the desired anticoagulant activities. ${ }^{9}$ One of Eberhard Mammen's scientific and clinical interests was the improvement of anticoagulant therapy for patients with venous and arterial thromboembolic diseases. In these fields, he focused his research on laboratory determinations and early clinical development of new anticoagulants.

The unmet clinical need of conventional anticoagulants should be overcome by novel synthetic anticoagulants inhibiting specifically only one activated coagulation factor. The main characteristics are rapid onset and offset of action, lack of need for routine monitoring and dose adjustment, lack or infrequent food and drug interactions, and probably better efficacy and safety compared with those of the conventional anticoagulants. The rapid onset and offset of action may avoid switching off and on with subcutaneous heparins as is required during anticoagulation with vitamin $\mathrm{K}$ antagonists. ${ }^{10-12}$

The development of new anticoagulants has therefore focused on synthetic small molecules to avoid the side effects or dose adjustment of the conventional anticoagulants. ${ }^{13}$ Factor $\mathrm{Xa}$ inhibitors act more upstream in the coagulation cascade compared with thrombin inhibitors. Small, indirect antithrombin dependent inhibitors inhibit factor $\mathrm{Xa}(\mathrm{FXa})$ in plasma but not factor $\mathrm{Xa}$ in the prothrombinase complex or bound to the fibrin clot. Small, direct synthetic molecules directed toward FXa and FIIa can neutralize their respective targets whether or not the targets are free in plasma, clot or prothrombinase-bound, an advantage over the indirect inhibitors that require antithrombin to mediate their effect. ${ }^{14,15}$ The advantage or disadvantage of this difference is open at present. This review focuses on the new synthetic and specific FXa inhibitors (Fig. 3).

\section{IDRAPARINUX}

Idraparinux is a polymethylated derivative of fondaparinux that binds antithrombin with high affinity, which results in increasing elimination half-life up to 60 days after a 6-month treatment period. After the first injection, the elimination half-life was calculated as 1 week, after 12 once-weekly injections as 25 days, and after 24 to 56 injections as 60 days. The steady state of idraparinux is obtained during chronic once-a-week subcutaneous administration after 240 to 300 days. ${ }^{16}$ Idraparinux may not require routine monitoring of anticoagulant intensity except in patients with renal impairment, in children, or in presence of bleeding complications. ${ }^{17}$ It does not interact with protamine, the antidote for heparin. Thus, if uncontrolled bleeding occurs, a procoagulant, such as recombinant factor VIIa, may be beneficial. ${ }^{18}$ Because of increased bleeding complications in the prolonged prophylaxis of venous thromboembolism (VTE) for 12 months compared with 6 months ${ }^{19,20}$ and during prophylaxis of embolism in patients with atrial fibrillation, ${ }^{21}$ further clinical development of idraparinux was stopped.

Pharmacokinetic analysis by the S2222 chromagenic anti-factor $\mathrm{Xa}$ assay and Heptest (Heptest Laboratories, Inc., St. Louis, MI) showed higher concentrations of idraparinux after 12 months than after 6 months of therapy $(p<0.0001)$. Because of the long half-life, idraparinux takes $\sim 240$ days to reach steadystate levels. This may explain the higher bleeding rate during long-term treatment. ${ }^{22,23}$

\section{BIOTINYLATED IDRAPARINUX}

The elimination of the anticoagulant activity of the new biotinylated idraparinux by avidin may offer an option for further improvement of anticoagulant treatment. $^{24}$ 


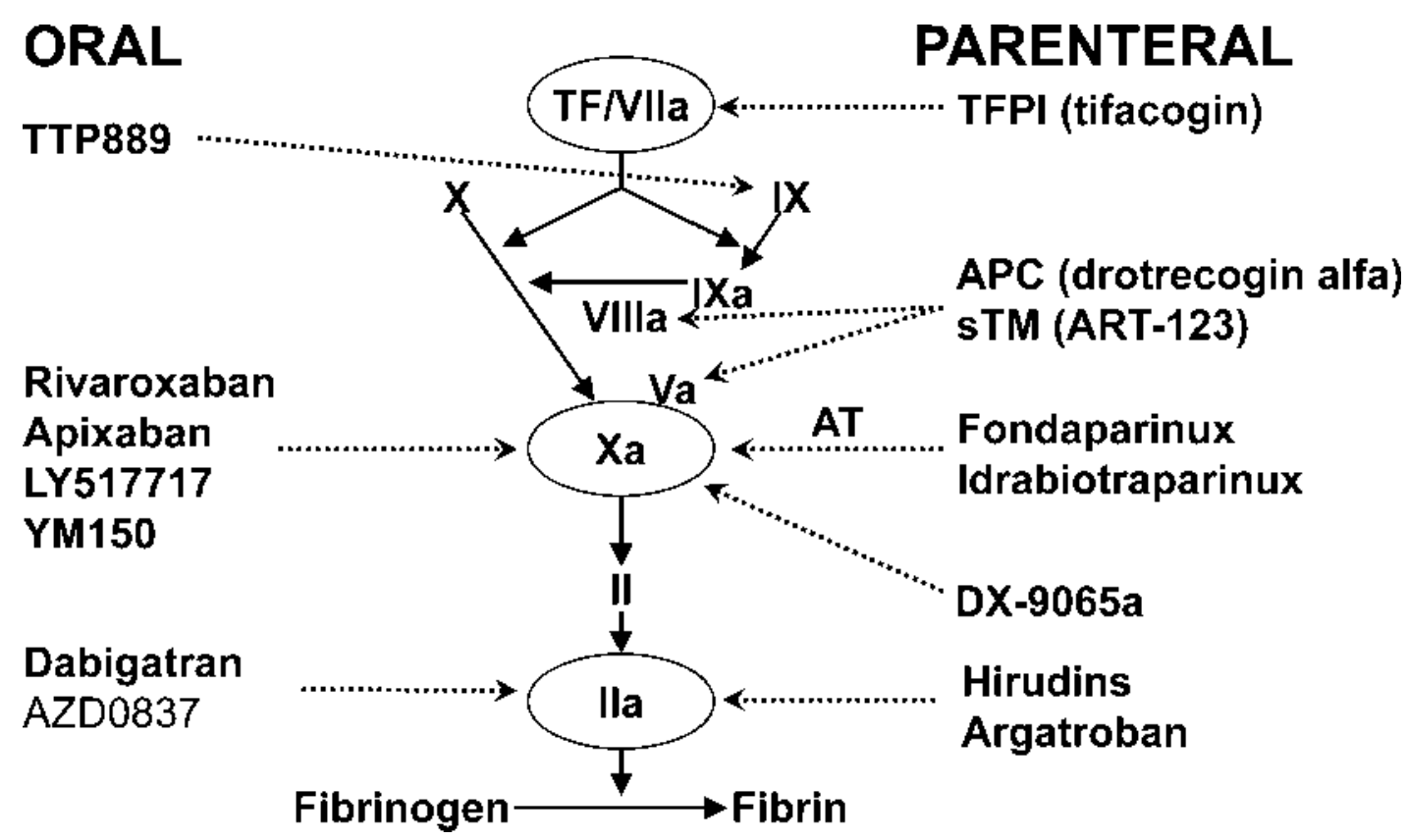

Figure 3 Overview of the targets of direct new oral and systemic-specific anticoagulant drugs.

Biotinylated idraparinux is structurally similar to idraparinux sodium with the addition of a biotin segment. It has the same anticoagulant activity as idraparinux in vivo and the same pharmacologic activity. Biotin has a strong and specific affinity for avidin, an egg protein, which can be given intravenously to rapidly bind, neutralize, and eliminate idraparinux and its anticoagulant activity. This is a new perspective for improving the shortcoming of idraparinux.

A bioequipotency study of biotinylated idraparinux and idraparinux includes 700 patients with DVT with a substudy on the neutralizing effect of avidin on the biotin-idraparinux-induced anti-FXa activity (EQUINOX study; ClinicalTrials.gov identifier NCT00311090).

Patients with symptomatic pulmonary embolism $(\mathrm{PE})$ are being treated in a randomized, double-blind, double-dummy, parallel group study with biotinylated idraparinux (3.0 $\mathrm{mg}$ subcutaneously once-weekly) versus oral international normalized ratio (INR)-adjusted warfarin in the treatment $(n=3200)$ (CASSIOPEA study; ClinicalTrials.gov identifier NCT00345618).

The multicenter, randomized, double-blind, noninferiority BOREALIS-AF study will compare the efficacy and safety of once-a-week subcutaneous biotinylated idraparinux with INR-adjusted warfarin in the prevention of stroke and systemic thromboembolic events in patients with atrial fibrillation for a treatment period of 6 months to 2 years. All patients start with $3 \mathrm{mg}$ biotinylated idraparinux (equivalent to $2.5 \mathrm{mg}$ idraparinux) once-a-week for 7 weeks, and then the dose will be reduced depending on age and renal function (http://en.sanofi-aventis.com/Images/ 070711_idraparinux_en_tcm24-18621.pdf).

\section{AVE5026}

AVE5026 is an ultralow-molecular-weight heparin with a mean molecular weight of $2500 \mathrm{Da}$ and an anti-FXa/ antithrombin ratio $>30$ (Sanofi Aventis, Paris, France). This compound is included in this overview because it inhibits thrombin to a very low extent. The anti-FXa/ antithrombin ratio of LMWH preparations ranges from 1.7 to $\sim 4$. The reduced inhibition of thrombin may improve the efficacy and safety compared with that of LMWHs.

A dose-finding phase IIb study was performed in patients undergoing total knee replacement for prevention of VTE using one subcutaneous injection daily compared with enoxaparin (TREK trial). According to the stratification of the patients, the first dose was administered 12 hours before or 8 hours after surgery. Six hundred seventy-eight patients were randomized to receive subcutaneously once-daily $5,10,20,40$, or $60 \mathrm{mg}$ AVE5026 or enoxaparin $40 \mathrm{mg}$ for 10 days after surgery. The primary efficacy outcome consisted of a combination of objectively confirmed asymptomatic DVT, symptomatic VTE, and VTE-related deaths. The end-point rates were $40.0 \%, 44.1 \%, 15.6 \%$, $13.6 \%$, and $5.3 \%$ for increasing doses of AVE5026, respectively, demonstrating the dose-dependent effect $(p<0.0001)$ compared with $35.8 \%$ in the enoxaparin group. Major bleeding rates increased from 0 to $3.4 \%$ with increasing doses of AV5026 $(p=0.02)$ compared with 0 in the enoxaparin group (Fig. 4). ${ }^{25}$ 


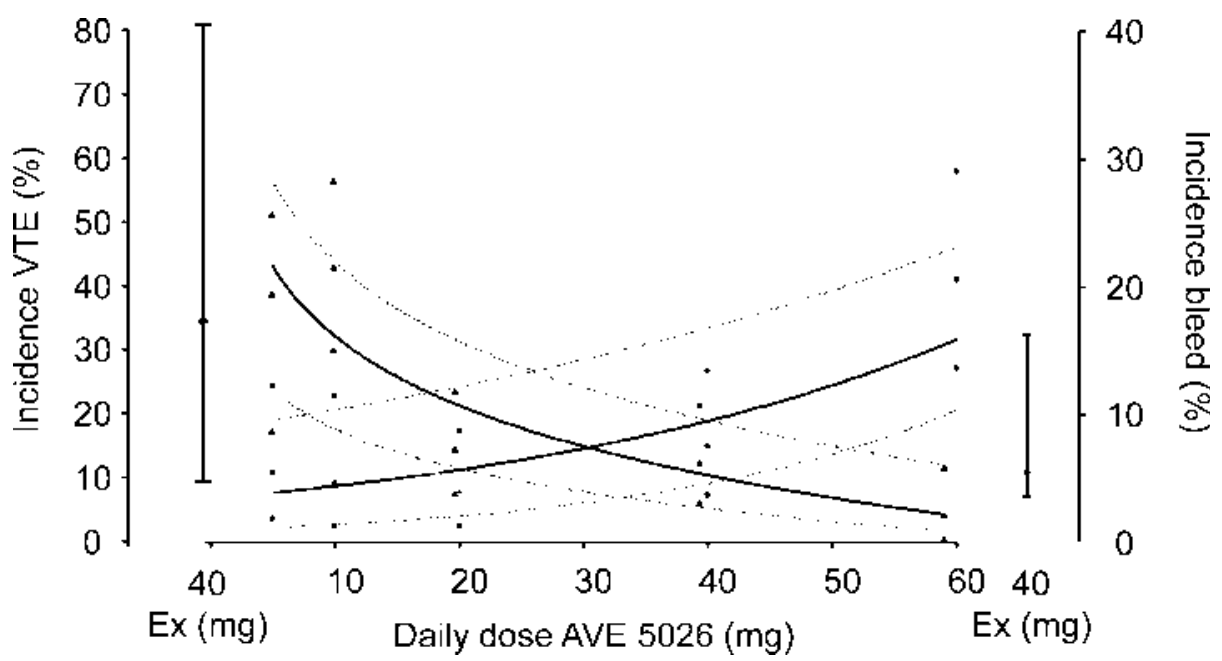

Figure 4 Dose-response relationships between AVE5026 and the incidences of VTE and bleeding. The lines are the mean dose-response curves for AVE5026 for the daily doses. The mean incidences of VTE (left y-axis) and of bleeding (right y-axis) are solid lines; the dotted lines represent the min and max values for VTE and the bleeding. The incidences of VTE and of bleeding during treatment with enoxaparin $40 \mathrm{mg}$ daily are shown on the right and left sides of the doses of AVE5026, respectively. Ex, enoxaparin.

\section{SR123781}

SR123781 is a short-acting synthetic hexadecasaccharide, injected once daily, and is an indirect antithrombin dependent inhibitor of FXa coagulation factors. The DRIVE phase IIb study evaluating the hexadecasaccharide in the prevention of venous thromboembolic events in patients undergoing total hip replacement (ClinicalTrials.gov identifier NCT00338897) demonstrated a correlation between dose and clinical response, with good efficacy and safety. The SHINE phase IIb study is evaluating SR123781 in patients with non-ST-elevation acute coronary syndrome (ClinicalTrials.gov identifier NCT00123565).

\section{DIRECT FACTOR Xa INHIBITORS}

\section{Otamixaban}

Otamixaban, \{2-(R)-(3-carbamoylimidoylbenzyl)-3$(R)$-[4-(1-oxypyridin-4-yl) benzoylamino]-butyric acid methyl ester, hydrochloride salt $\}$ is a direct potent and selective inhibitor of FXa. It is administered intravenously. Otamixaban inhibits FXa in human plasma with a $\mathrm{K}_{\mathrm{i}}$ of $0.52 \mathrm{nM}(0.25 \mathrm{ng} / \mathrm{mL})$. The preclinical pharmacokinetics of otamixaban is characterized by a fast systemic clearance $\left(\mathrm{t}_{1 / 2}=0.5\right.$ to 1.5 hours). The renal excretion accounted for 13 to $32 \%$ of the total dose administered. ${ }^{26}$ Otamixaban was investigated in patients undergoing nonurgent percutaneous coronary intervention in a double-blind, double-dummy, parallel-group, dose-ranging trial, including more than 900 patients randomly assigned to 1 of 5 weight-adjusted otamixaban regimens or weight-adjusted UFH. Otamixaban (or placebo) was given as a weight-adjusted intravenous bolus followed by a 3-hour infusion (dose $1=$ $0.025 \mathrm{mg} / \mathrm{kg}$ followed by $0.035 \mathrm{mg} \mathrm{kg}{ }^{-1} \mathrm{~h}^{-1}$; dose $2=0.045 \mathrm{mg} / \mathrm{kg}$ followed by $0.065 \mathrm{mg} \mathrm{kg}^{-1} \mathrm{~h}^{-1}$; dose $3=0.080 \mathrm{mg} / \mathrm{kg}$ followed by $0.120 \mathrm{mg} \mathrm{kg}^{-1} \mathrm{~h}^{-1}$; dose $4=0.120 \mathrm{mg} / \mathrm{kg}$ followed by $0.160 \mathrm{mg} \mathrm{kg}^{-1} \mathrm{~h}^{-1}$; and dose $5=0.140 \mathrm{mg} / \mathrm{kg}$ followed by $0.200 \mathrm{mg} \mathrm{kg}^{-1} \mathrm{~h}^{-1}$ ). UFH (or placebo) was given as a weight-adjusted intravenous bolus (50 to $70 \mathrm{U} / \mathrm{kg}$ ) just before percutaneous coronary intervention (PCI). The primary end points were change in prothrombin fragments $1+2(\mathrm{~F} 1+2)$, and anti-FXa activity. The main secondary end points were thrombolysis in myocardial infarction (TIMI) bleeding at day 3 or hospital discharge (whichever came first) and 30-day ischemic events. The median change in $\mathrm{F} 1+2$ from baseline to the end of infusion was greater with the highest otamixaban dose compared with UFH. Anti-FXa levels were 65, 155, 393, 571, and $691 \mathrm{ng} / \mathrm{mL}$ with otamixaban doses 1 to 5 , respectively. Significant TIMI bleeding (major or minor) occurred in $2.0 \%, 1.9 \%, 3.8 \%, 3.9 \%$, and $2.6 \%$ of patients receiving otamixaban doses 1 to 5 , respectively, and in $3.8 \%$ of patients receiving UFH. Four TIMI major bleeds were observed. Ischemic events occurred in 5.8\%, 7.1\%, 3.8\%, $2.5 \%$, and $5.1 \%$ of patients receiving otamixaban doses 1 to 5 , respectively, and in $5.6 \%$ of patients receiving UFH. Otamixaban reduced $\mathrm{F} 1+2$ significantly more than did UFH at the highest dose regimen, whereas no significant difference in the incidence of TIMI bleeding was observed between the otamixaban and UFH groups. ${ }^{27}$

\section{DX-9065a}

DX-9065a is a direct, small-molecule $(571.07 \mathrm{Da})$, selective, reversible FXa inhibitor that because of its 
small size is able to inhibit both free FXa and FXa within the prothrombinase complex. ${ }^{28} \mathrm{XaNADU}-\mathrm{ACS}$ was a phase II, multicenter, international, randomized, double-blinded, double-dummy, active-controlled study in patients with non-ST-elevation acute coronary syndrome. The composite end point of death, myocardial infarction (MI), or urgent revascularization occurred in $19.5 \%$ of patients assigned to heparin, $19.3 \%$ of patients assigned to low-dose DX-9065a, and $11.9 \%$ of patients assigned to high-dose DX-9065a (not significant). Patients assigned to low-dose DX-9065a received a bolus $(0.025 \mathrm{mg} / \mathrm{kg})$, a 3-hour loading infusion $(0.04$ $\left.\mathrm{mg} \mathrm{kg}{ }^{-1} \mathrm{~h}^{-1}\right)$, and a maintenance infusion $(0.012 \mathrm{mg}$ $\mathrm{kg}^{-1} \mathrm{~h}^{-1}$ ) of DX-9065a. Those patients assigned to high-dose DX-9065a received a bolus $(0.05 \mathrm{mg} / \mathrm{kg})$, a 3-hour loading infusion $\left(0.08 \mathrm{mg} \mathrm{kg}^{-1} \mathrm{~h}^{-1}\right)$, and a maintenance infusion $\left(0.024 \mathrm{mg} \mathrm{kg}^{-1} \mathrm{~h}^{-1}\right)$ of DX9065a. Patients assigned to either low- or high-dose DX-9065a tended to have less bleeding and required fewer transfusions than did those assigned to heparin. Rates of major or minor bleeding were similar among patients assigned to heparin (7.7\%) and high-dose DX$9065 \mathrm{a}(7.0 \%)$ but tended to be lower $(4.0 \%)$ in patients assigned to low-dose DX-9065a. ${ }^{29}$

\section{Rivaroxaban}

Rivaroxaban, 5-chloro- $N$ - $(\{(5 S)-2$-oxo-3-[4-(3-oxomorpholin-4-yl)phenyl]-1,3-oxazolidin-5-yl\}methyl) thiophene-2-carboxamide, is a competitive, reversible, direct FXa inhibitor with a $\mathrm{K}_{\mathrm{i}}$ of $0.4 \mathrm{nM}$ for purified human FXa and a molecular mass of 435.89. After oral administration in man, it is $60 \%$ to $80 \%$ absorbed. Peak plasma levels are achieved in 3 hours, and the drug circulates with a half-life of 9 hours. In phase I studies, the $t_{1 / 2}$ was between 5.8 and 9.2 hours after oral administration in healthy volunteers and 11 to 12 hours in those above 70 years of age as determined by the inhibition of FXa. Rivaroxaban has a dual mode of excretion, via the renal (66\%) and fecal/biliary (28\%) routes, and is mainly excreted as unchanged drug. Coadministration of rivaroxaban with food increased the peak plasma concentrations slightly. No additive effects on platelet aggregation were observed when rivaroxaban was coadministered with either aspirin or the nonsteroidal anti-inflammatory drug naproxen, antacid drugs, or digoxin. Because of the predominance of the renal pathway of excretion, the half-life of rivaroxaban is prolonged in the elderly and in patients with renal impairment. ${ }^{30}$ The results of the dose-finding study for rivaroxaban in postoperative medicine is shown in Fig. $5 .^{31}$

\section{POSTOPERATIVE PREVENTION OF VTE}

A total of 2531 patients undergoing total knee arthroplasty (TKA) were randomized to rivaroxaban $10 \mathrm{mg}$ daily or subcutaneous enoxaparin $40 \mathrm{mg}$ daily. Enoxaparin was initiated 12 hours before surgery and

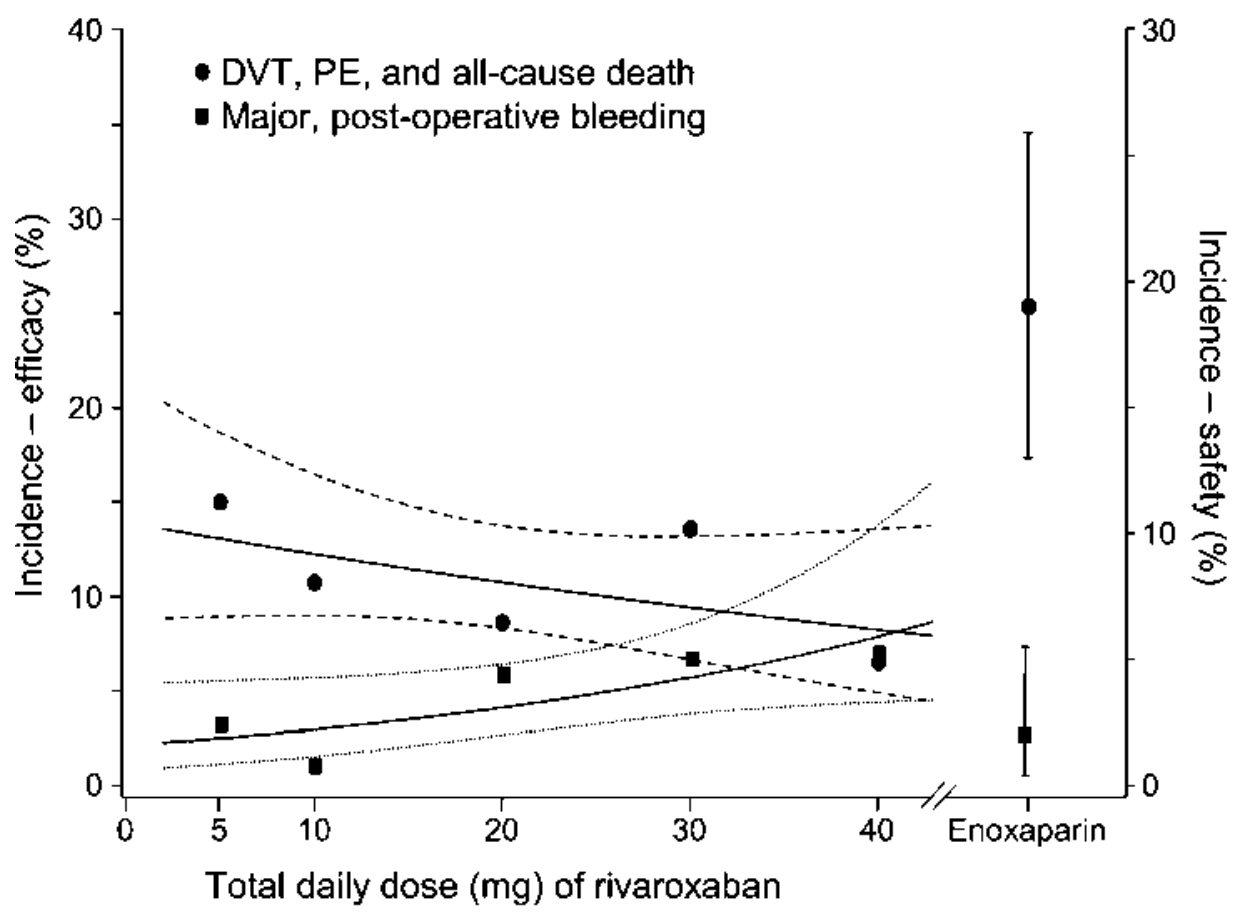

Figure 5 Dose-response relationships between rivaroxaban and the primary efficacy end point and the primary safety end point. The solid lines are the dose-response curves for rivaroxaban, estimated by logistic regression including total daily dose as a covariate. The dotted lines represent the 95\% confidence intervals for safety. The hatched lines represent the 95\% confidence intervals for efficacy. (From Kubitza D, Haas S. Novel factor Xa inhibitors for prevention and treatment of thromboembolic diseases. Expert Opin Investig Drugs 2006;15:843-855. Reprinted with permission.) 
rivaroxaban 6 to 8 hours after surgery for 10 to 14 days. The primary efficacy end point was the composite of any DVT, nonfatal PE, and all-cause mortality. This efficacy outcome occurred in $9.6 \%$ of patients receiving rivaroxaban compared with $18.9 \%$ of patients receiving enoxaparin (relative risk reduction 49\%; $p<0.001$ ). The incidences of major and nonmajor bleeding were similar in both the rivaroxaban and enoxaparin groups. $^{32}$

The short-term thromboprophylaxis using enoxaparin was compared with extended thromboprophylaxis for up to 5 weeks using rivaroxaban in 2509 patients undergoing total hip replacement (THR) in a prospective, randomized, double-blind clinical trial. Patients received $40 \mathrm{mg}$ enoxaparin daily, beginning the evening before surgery and continuing for 10 to 14 days followed by placebo until day 35 , or received rivaroxaban $10 \mathrm{mg}$ daily beginning 6 to 8 hours after surgery for 35 days. The primary outcome was the composite of DVT, PE, and all-cause mortality. The primary composite end point was $9.3 \%$ in the enoxaparin group and $2.0 \%$ in the rivaroxaban group (relative risk reduction of $79 \%$, $p<0.001)$. The incidences of major and nonmajor bleeding were similar in both groups $(p=0.246){ }^{33}$

RECORD1 was a phase III, multinational, randomized, double-blind, double-dummy trial to determine the efficacy and safety of $1 \times 10 \mathrm{mg}$ rivaroxaban starting 6 to 8 hours after surgery compared with $1 \times$ $40 \mathrm{mg}$ enoxaparin initiated the evening before surgery, both for 35 days in 4541 patients undergoing THR. The primary outcome was the composite of DVT, PE, and all-cause mortality. This efficacy end point occurred in $1.1 \%$ of patients randomized to rivaroxaban and in $3.7 \%$ of patients randomized to enoxaparin (relative risk reduction of $70 \%$; $95 \%$ confidence interval, 49 to $82 \%$; $p<0.001)$. The incidence of major and nonmajor bleeding events was similar in both groups. ${ }^{34}$

The pharmacokinetic/pharmacodynamic (PK/ $\mathrm{PD}$ ) of rivaroxaban was analyzed from 870 patients during treatment of acute DVT using nonlinear, mixed-effect population modeling (NONMEM). Rivaroxaban $\mathrm{C}_{\max }$ and $\mathrm{C}_{\text {trough }}$ concentrations increased dose dependently. As expected, $\mathrm{C}_{\max }$ was higher and $\mathrm{C}_{\text {trough }}$ was lower after daily dosing compared with twice-daily dosing, at equivalent total daily doses; however, $90 \%$ confidence intervals overlapped. Rivaroxaban plasma concentrations correlated linearly with PT. Comedications (e.g., diuretics, NSAIDs, aspirin) had no relevant effects on the PK of rivaroxaban. ${ }^{35}$

\section{TREATMENT OF ACUTE VTE}

The randomized, parallel-group, phase II trial in patients with proximal DVT explored the efficacy and safety of rivaroxaban 10,20 , or $30 \mathrm{mg}$ twice daily or 40 $\mathrm{mg}$ once daily compared with enoxaparin $1 \mathrm{mg} / \mathrm{kg}$ twice daily followed by vitamin $\mathrm{K}$ antagonist for 12 weeks. The primary efficacy outcome was an improvement in thrombotic burden at day 21 (defined as a $\geq 4$-point reduction in the thrombus score as measured by compression ultrasound examination). The thrombus burden was less than 4 points in 53 of 100, 58 of 98, 62 of 109 , and 49 of 112 patients receiving rivaroxaban 10,20 , or $30 \mathrm{mg}$ twice daily or $40 \mathrm{mg}$ once daily, respectively, compared with 50 of 109 patients treated with enoxaparin/vitamin K antagonist (VKA). The primary efficacy end point was therefore achieved. There was no dose-response relationship between rivaroxaban and the primary efficacy end point $(p<0.67)$ and no difference with patients randomized to enoxaparin/VKA. Major bleeding was observed in $1.7 \%, 1.7 \%, 3.3 \%$, and $1.7 \%$ of patients receiving rivaroxaban 10,20 , or $30 \mathrm{mg}$ twice daily or $40 \mathrm{mg}$ daily and 0 of enoxaparin/VKA patients. There were no major bleeding events during the treatments. ${ }^{36}$

The incidence of alanine aminotransferase (ALT) elevations greater than threefold upper limit of normal (ULN) in the rivaroxaban groups ranged from 1.9 to $4.3 \%$ compared with $21.6 \%$ in the enoxaparin/VKA-treated group. Rivaroxaban was stopped prematurely in three patients because of elevated liver enzyme levels.

The Einstein study is the second phase II trial evaluating the efficacy and safety of rivaroxaban for the treatment of acute DVT of similar design but compared once-daily rivaroxaban $(20,30$, or $40 \mathrm{mg})$ with a heparin (either unfractionated or LMWH), followed by a VKA, in 543 patients with symptomatic DVT without symptomatic PE. The primary efficacy outcome (deterioration in thrombotic burden or symptomatic recurrent VTE) occurred in 5.4 to $6.6 \%$ of patients on rivaroxaban and $9.9 \%$ on heparin/VKA. There was no evidence of a dose-efficacy relationship with rivaroxaban. During the first 3 weeks of treatment, the incidence of ALT elevations $>3$ times the ULN was lower in patients on rivaroxaban. ${ }^{37}$ On the basis of these trials, the $20 \mathrm{mg}$ once-daily dose of rivaroxaban has been chosen for evaluation in phase III randomized trials.

In a phase III trial, rivaroxaban $1 \times 20 \mathrm{mg}$ is being investigated in $\sim 6200$ patients with acute symptomatic DVT or PE and compared for prevention of recurrent VTE with initial anticoagulation with body-weightadjusted enoxaparin followed by INR-adjusted warfarin for 3 to 12 months (www.ClinicalTrials.gov identifier NCT00440193 [Einstein Study]).

The prolonged prophylaxis of VTE is being investigated in patients with an initial prophylaxis of VTE for 3 to 12 months and no indication for further anticoagulation. These patients are randomized to rivaroxaban $1 \times 20 \mathrm{mg}$ or placebo in a double-blind, prospective, randomized clinical trial for 6 or 12 months according to the decision of the physician (EINSTEIN EXTENSION; ClinicalTrials.gov identifier NCT00439725). 


\section{ATRIAL FIBRILLATION}

In patients with nonvalvular atrial fibrillation, rivaroxaban is being compared with INR-adjusted dose oral warfarin for prevention of stroke in a double-blind, double-dummy, prospective randomized trial in $\sim 14,000$ patients. Patients with a reduced creatinine clearance between 30 and $49 \mathrm{~mL} / \mathrm{min}$ receive a reduced dose of $15 \mathrm{mg}$ rivaroxaban once daily. The primary composite outcome event consists of embolic and nonembolic stroke and non-cerebral nervous system systemic embolism. The secondary outcome end points are a composition of stroke, non-cerebral nervous system systemic embolism, and vascular death (Rocket trial; ClinicalTrials.gov identifier NCT 004403767).

The efficacy and safety of rivaroxaban for the prevention of stroke and embolism in 1200 subjects with nonvalvular atrial fibrillation are currently being investigated in a prospective, randomized, double-blind, phase III trial in Japan (www.ClinicalTrials.gov identifier NCT00494871).

\section{ACUTE CORONARY SYNDROME}

In patients with acute coronary syndrome, a randomized, double-blind, placebo-controlled, multicenter, doseescalating phase IIb study is being performed to evaluate the safety and efficacy of rivaroxaban in combination with aspirin alone or with aspirin and clopidogrel in 1350 patients. The primary outcome measure is the combined incidence of fatal and major bleeding complications (Atlas ACS TIMI 46 trial; ClinicalTrials.gov identifier NCT00402597). The results will be published at the American Heart Association Congress in November 2008.

\section{Apixaban}

Apixaban is a follow-up compound to the oral, direct $\mathrm{FXa}$ inhibitor razaxaban and is a selective and potent $\left(\mathrm{K}_{\mathrm{i}}=0.08 \mathrm{nM}\right)$ inhibitor of both free and prothrombinase-bound FXa in human plasma. In animal models, the compound had an oral bioavailability of $51 \%, 88 \%$, and $34 \%$ in chimpanzees, dogs, and rats, respectively, was eliminated by renal and fecal excretion, with minimal if at all drug-drug interactions and formed no active metabolites. After oral administration in human, the compound is $80 \%$ absorbed within 3.5 hours and is eliminated with a half-life ranging from 8 to 15 hours. Seventy-five percent of it is eliminated by urinary excretion. $^{38}$ It demonstrated potent antithrombotic effects in a rabbit model of venous thrombosis.

Apixaban is currently being explored in the EXPANSE clinical trial program, which includes eight phase III clinical studies involving $\sim 45,000$ patients worldwide.

\section{POSTOPERATIVE PREVENTION OF VTE}

A phase IIb study for the prevention of VTE in patients undergoing TKR compared 5, 10, or $20 \mathrm{mg}$ apixaban once- or twice-daily with open-label enoxaparin or warfarin for 10 to 14 days in 1217 patients. The primary efficacy end point consisted of DVT confirmed by bilateral venogram, symptomatic DVT, nonfatal PE, and death from any cause. The incidences ranged from 5 to $12.5 \%$, respectively, compared with $15.6 \%$ in the enoxaparin group and $26.6 \%$ in the warfarin group resulting in a relative risk reduction ranging from 21 to $69 \%$ when compared with enoxaparin and from 53 to $82 \%$ when compared with warfarin (Fig. 6). Total VTE

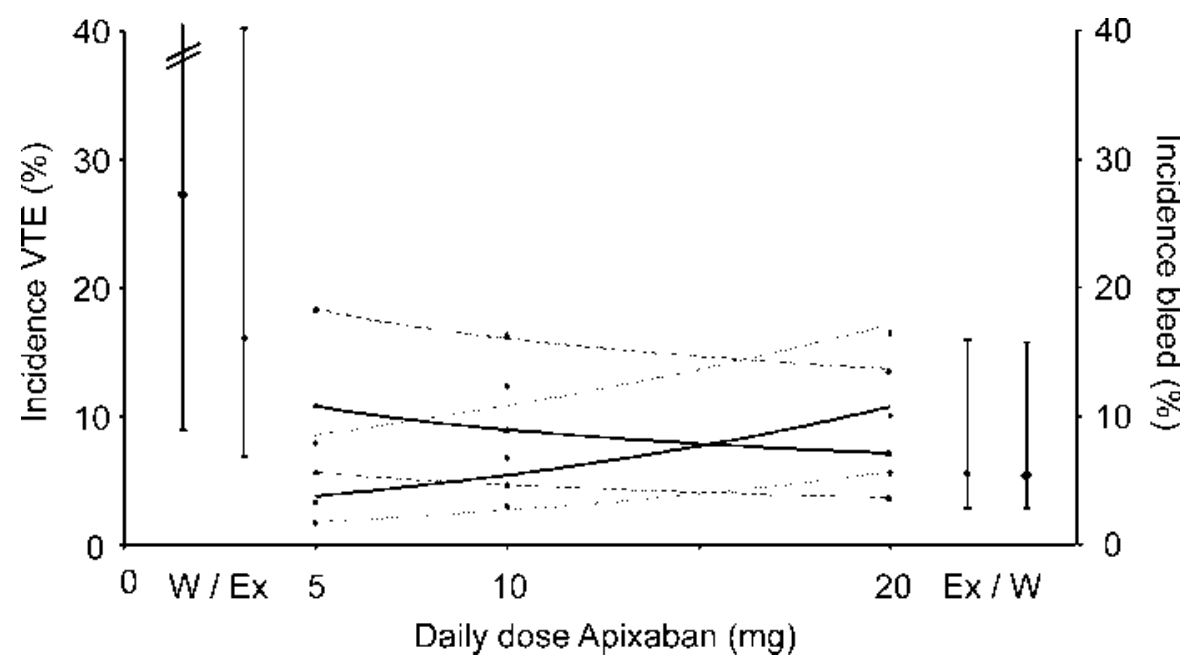

Figure 6 Dose-response relationships between apixaban and the incidences of VTE and bleeding. The lines are the mean dose-response curves for apixaban for the daily doses. The mean incidences of VTE (left y-axis) and of bleeding (right y-axis) are solid lines; the dotted lines represent the min and max values for VTE and the bleeding. The incidences of VTE and of bleeding during treatment with enoxaparin $40 \mathrm{mg}$ daily and warfarin are shown on the right and left sides of the doses of apixaban, respectively. W, warfarin; Ex, enoxaparin. 
rates were lower in the twice-daily apixaban groups than in the once-daily apixaban groups.

The incidence of major bleeding among apixaban-treated patients ranged from 0 ( $2.5 \mathrm{mg}$ twice daily) to $3.3 \%$ (20 $\mathrm{mg}$ once daily). The overall incidences of minor bleeding during apixaban, enoxaparin, and warfarin treatments were $7.2 \%, 4.0 \%$, and $5.3 \%$, respectively. A dose-related response was noted for the incidence of minor bleeding across the once-daily apixaban treatment groups $(p=0.01)$ but not for the twice-daily groups $(p=0.07)$. There were no differences between once-daily and twice-daily dose groups (Fig. 6).

Two patients (apixaban $10 \mathrm{mg}$ twice daily and warfarin) had a single, concurrent elevation in ALT $>3$ times ULN and total bilirubin $>2$ times ULN on postoperative day 1 , which returned to below these thresholds by the next evaluation and to within normal limits by the end of the treatment period (apixaban subject) or at the 30-day follow-up period (warfarin subject) with continued drug dosing. ${ }^{39}$

The ADVANCE-2 and 3 trials are investigating the safety and efficacy of apixaban $2.5 \mathrm{mg}$ twice daily compared with enoxaparin $40 \mathrm{mg}$ once daily in more than 4000 patients undergoing elective total hip replacement surgery regarding the incidence of asymptomatic and symptomatic DVT, PE, and all-cause mortality over 35 days. Secondary outcome measures are major and nonmajor bleeding events (ClinicalTrials.gov identifier NCT00423319).

\section{TREATMENT OF ACUTE VTE}

In a phase IIb dose-ranging study, the efficacy and safety of apixaban was evaluated in patients with confirmed, acute DVT. Patients were allocated randomly to one of three double-blind regimens of apixaban $(5 \mathrm{mg}$ twice daily, $10 \mathrm{mg}$ twice daily, or $20 \mathrm{mg}$ daily), or conventional treatment with LMWH or fondaparinux followed by open-label VKA adjusted to an INR 2.0 to 3.0. Five hundred twenty patients were included and treated for 84 to 91 days. The primary efficacy outcome was the composite of symptomatic recurrent VTE and deterioration of the thrombotic burden as assessed by repeat bilateral venous compression ultrasound (CUS) of the legs and pulmonary lung scan. The principal safety outcome was a composite of major and clinically relevant nonmajor bleeding (Boticelli trial).

For apixaban $5 \mathrm{mg}$ twice daily, $10 \mathrm{mg}$ twice daily, $20 \mathrm{mg}$ daily, and for VKA, the primary efficacy outcome rates were $6.0 \%, 5.6 \%, 2.6 \%$, and $4.2 \%$, respectively. The principal safety outcome rates were $8.6 \%, 4.5 \%, 7.3 \%$, and $7.9 \%$, respectively. The rates of symptomatic VTE were $2.6 \%, 3.2 \%, 1.7 \%$, and $2.5 \%$, respectively. The rates of major bleeding were $0.8 \%$ (5 mg twice daily), 0 (10 mg twice daily), $0.8 \%$ (20 mg daily), and 0 (enoxaparin/ warfarin). A fixed dose of apixaban seems to be as safe as enoxaparin/warfarin for treatment of acute VTE. ${ }^{40}$
The VTE treatment program consists of two trials. The AMPLIFY trial is a 6-month trial investigating apixaban compared with enoxaparin plus warfarin in $\sim 4800$ patients with acute DVT or PE. The AMPLIFY-EXT trial is a 12-month trial investigating apixaban compared with placebo for extended treatment to prevent recurrent VTE in $\sim 2400$ patients who have completed 6 to 12 months of treatment for DVT or PE.

The randomized, double-blind, double-dummy, clinical noninferiority trial compares $10 \mathrm{mg}$ twice-daily apixaban with initial body-weight-adjusted enoxaparin followed by INR-adjusted warfarin in $\sim 5800$ patients with acute DVT and PE. Primary objectives are the incidences of recurrent VTE or VTE-related death over 6 months.

The prolonged prophylaxis after an acute episode of VTE is being investigated using apixaban versus placebo in those patients with no indication for a prolonged prophylaxis of VTE using VKA. Apixaban $2.5 \mathrm{mg}$ twice daily is being compared with $5 \mathrm{mg}$ apixaban twice daily and placebo twice daily for 12 months. The primary end point of recurrent VTE is a determination of at least one of the apixaban dose regimens to be superior to placebo. The combined end point consists of symptomatic recurrent VTE and all-course mortality in subjects who have completed a standard of 6 to 12 months of conventional anticoagulation for prevention of a symptomatic DVT or PE in $\sim 650$ patients per group.

\section{ACUTE CORONARY SYNDROME}

The APPRAISE-1 study was a double-blind, placebocontrolled, dose-ranging study to evaluate the safety and efficacy of apixaban $(2.5 \mathrm{mg}$ twice daily, $10 \mathrm{mg}$ once daily, $10 \mathrm{mg}$ twice daily, or $20 \mathrm{mg}$ once daily) over a 26-week treatment period in 1715 patients presenting with acute coronary syndrome (ACS). All patients received aspirin $\leq 165 \mathrm{mg} /$ day. The use of clopidogrel was left to the discretion of the treating physician. The primary end point of the study was the incidence of International Society on Thrombosis and Haemostasis (ISTH)-defined major bleeding and clinically relevant nonmajor bleeding. The composite efficacy end point was the amount of time from patient randomization to the first occurrence of a combination of cardiovascular events including cardiovascular death, nonfatal heart attack, severe recurrent ischemia, and nonhemorrhagic stroke (European Society of Cardiology [ESC] Congress 2008, Munich, Germany).

The incidence of the primary end point of this safety study, major bleeding plus clinically relevant nonmajor bleeding, was $5.7 \%$ for apixaban patients who took the $2.5 \mathrm{mg}$ twice-daily dose $(n=315), 7.9 \%$ for patients who took the $10 \mathrm{mg}$ once-daily dose $(n=315)$, and $3.0 \%$ for patients who took placebo $(n=599)$. The bleeding scale used in the APPRAISE- 1 trial was the 
comprehensive ISTH standard. The incidence of major ISTH bleeding was $0.8 \%$ with placebo $(n=599)$ versus $1.6 \%$ and $1.9 \%$ with the $2.5 \mathrm{mg}$ twice-daily $(n=315)$ and $10 \mathrm{mg}$ once-daily $(n=315)$ doses, respectively. Results for major bleeding measured using the more commonly used TIMI scale, in a post hoc assessment, were $0.3 \%(n=599)$ for placebo, $0.0(n=315)$ for the $2.5 \mathrm{mg}$ twice-daily apixaban dose, and $1.0 \%(n=315)$ for the $10 \mathrm{mg}$ once-daily apixaban dose. Two additional arms of the study that examined higher doses, $10 \mathrm{mg}$ twice daily and $20 \mathrm{mg}$ once daily, were stopped early due to increased total bleeding.

The incidence of adverse events, serious adverse events, and discontinuations due to adverse events was similar for all treatment groups. The discontinuation rates for bleeding events were $1.2 \%$ with placebo, $1.9 \%$ with the $2.5 \mathrm{mg}$ twice-daily dose, and $2.9 \%$ with the $10 \mathrm{mg}$ once-daily dose. The incidence of liver function test abnormalities after 6-month dosing was similar with apixaban and placebo. The frequencies of ALT elevations above threefold the ULN were $2.7 \%, 0$, and $1.0 \%$ for the placebo, $2.5 \mathrm{mg}$ twice-daily apixaban, and $10 \mathrm{mg}$ once-daily apixaban groups, respectively.

\section{OTHER INDICATIONS}

Apixaban is also in phase III trials studying the prevention of stroke and other thromboembolic events in patients with atrial fibrillation (AF) and studying the treatment of VTE. The AF program consists of two trials. The ARISTOTLE trial is investigating apixaban compared with warfarin in $\sim 15,000$ patients with atrial fibrillation for the prevention of stroke and systemic embolism in patients with nonvalvular AF. Secondary outcome measures are confirmed ischemic stroke, hemorrhagic stroke, systemic embolism, and all-cause death. This randomized, double-blind, parallel-arm study is expected to enroll 15,000 patients (ClinicalTrials. gov identifier NCT00412984).

The AVERROES trial is investigating apixaban compared with aspirin in $\sim 5600$ patients with atrial fibrillation who are ineligible for VKA treatment or have not tolerated previous VKA treatment. Patients are randomized to $2 \times 2.5 \mathrm{mg}$ apixaban versus acetylsalicylic acid (81 to $324 \mathrm{mg}$ daily) in a double-blind design and treated for up to 3 years. The study hypothesis is the superiority of apixaban to acetylsalicylic acid for preventing the combined outcome of stroke or systemic embolism in 5600 patients with $\mathrm{AF}$ with at least one additional risk factor for stroke (ClinicalTrials.gov identifier NCT00496769)

The ADOPT study is investigating the safety and efficacy of $2 \times 2.5 \mathrm{mg}$ apixaban/placebo compared with $1 \times 40 \mathrm{mg}$ enoxaparin/placebo for 6 to 15 days followed by apicaban/placebo for 35 to 45 days in acutely ill, hospitalized medical subjects for prophylaxis of VTE (ClinicalTrials.gov identifier NCT00457002).

Another study currently under way is investigating apixaban for the prevention of thromboembolic events in patients with advanced metastatic cancer and is expected to enroll 160 patients (ClinicalTrials.gov identifier NCT00320255).

\section{YM150}

The compound is an orally active, direct FXa inhibitor ${ }^{41}$ and was investigated in patients $(n=174)$ undergoing hip replacement surgery to assess the safety and efficacy of thromboprophylaxis in a dose-escalation study (ONYX-study). Patients were randomized per cohort

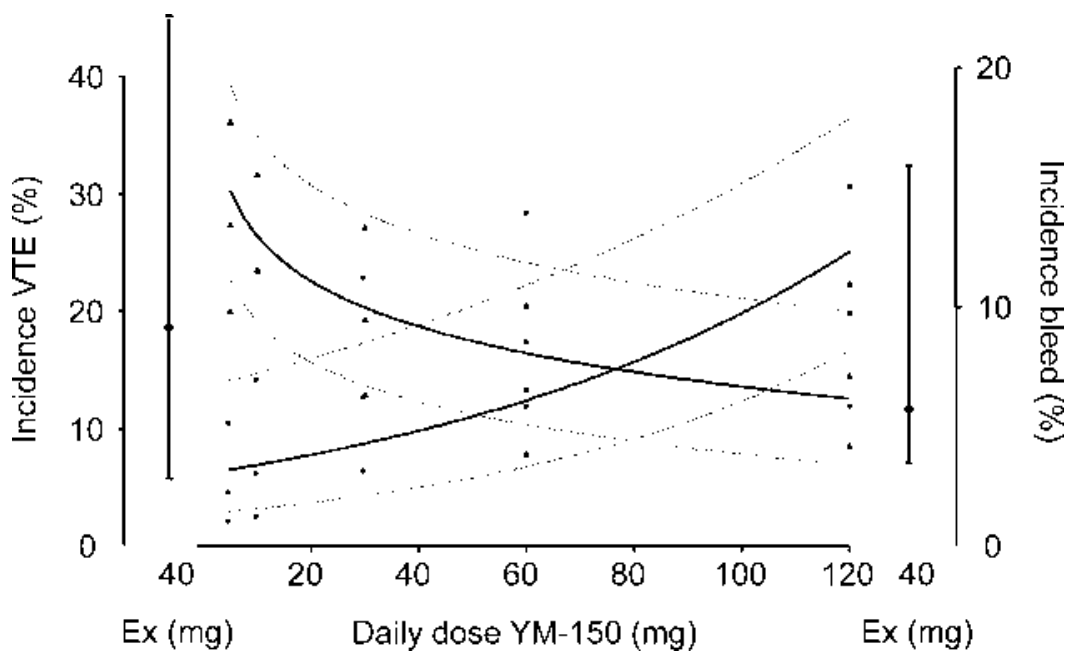

Figure 7 Dose-response relationships between YM150 and the incidences of VTE and bleeding. The lines are the mean doseresponse curves for YM150 for the daily doses. The mean incidences of VTE (left y-axis) and of bleeding (right y-axis) are solid lines; the dotted lines represent the min and max values for VTE and the bleeding. The incidences of VTE and of bleeding during treatment with enoxaparin $40 \mathrm{mg}$ daily are shown on the right and left sides of the doses of YM150, respectively. Ex, enoxaparin. 
to oral once-daily $3,10,30$, and $60 \mathrm{mg}$ YM150 or subcutaneous enoxaparin (40 $\mathrm{mg}$ daily) for 7 to 10 days treatment. No major and three clinically relevant nonmajor bleeds were reported, one in the $3 \mathrm{mg}$ and two in the $10 \mathrm{mg}$ groups. The efficacy analysis showed a doserelated trend in the reduced incidence of venographically demonstrated DVT with increasing dose of YM150 $(p=0.006){ }^{42}$

A double-blind, dose-finding, phase IIb study (ONYX-2) was performed in patients undergoing elective hip replacement surgery versus open-label enoxaparin. A total of 1071 patients were treated in-hospital and thereafter at home up to 6 weeks with $5,10,30,60$, or $120 \mathrm{mg}$ YM150 or $40 \mathrm{mg}$ enoxaparin once-daily subcutaneously (ClinicalTrials.gov identifier NCT00353678). The incidences of VTE were 27.4\%, 31.7\%, 19.3\%, $13.3 \%$, and $14.5 \%$ in patients receiving increasing doses of 5, 10, 30, 60, or $120 \mathrm{mg}$ YM150 versus $19.8 \%$ in patients randomized to enoxaparin. The corresponding figures for bleeding complications were $2.5 \%, 3.2 \%$, $6.5 \%, 8.7 \%$, and $9.7 \%$ for the YM150 group versus $5.4 \%$ for the enoxaparin group. ${ }^{43}$ The mean values and standard deviations were used to create Fig. 7.

\section{LY517717}

LY517717 was shown to have a $\mathrm{K}_{\mathrm{i}}$ of 4.6 to $6.6 \mathrm{nM}$ on FXa. ${ }^{44}$ A phase II, double-blind, double-dummy, doseranging study was initiated to determine the efficacy and safety of LY517717, compared with enoxaparin, for the prevention of VTE in patients undergoing TKR or THR. Patients $(n=511)$ were randomized to receive oral LY517717 (25, 50, 75, 100, 125, or $150 \mathrm{mg}$ daily) or enoxaparin $40 \mathrm{mg}$ daily. Because of lack of efficacy, the three lowest LY517717 dose arms were stopped early and the study was completed with the three highest doses only. The 100, 125, and $150 \mathrm{mg}$ daily doses of LY517717 were not inferior to enoxaparin, with similar incidences of the efficacy end point ( 17.1 to $24.0 \%$ vs. $22.2 \%$ with enoxaparin) and lower incidences of major bleeding ( 0.0 to $0.9 \%$ vs. $1.1 \%$ with enoxaparin) and minor bleeding (0.0 to $1.0 \%$ vs. $2.2 \%$ with enoxaparin). ${ }^{45}$ The incidences of recurrent VTE and of bleeding are depicted in Fig. 8.

\section{DU-176b}

The $\mathrm{K}_{\mathrm{i}}$ of DU-176b for human FXa is $\sim 10,000$ times lower than the lowest $\mathrm{K}_{\mathrm{i}}$ value for any other human serine proteases (thrombin). A phase IIa, open-label, dose-finding study of DU-176b for the prevention of VTE after THR was initiated (ClinicalTrials.gov identifier NCT00107900) involving 600 patients.

In patients with $\mathrm{AF}$, four dose regimens of DU$176 \mathrm{~b}(1 \times 30 \mathrm{mg}, 2 \times 30 \mathrm{mg}, 1 \times 60 \mathrm{mg}$, and $2 \times 60 \mathrm{mg}$ daily by mouth) are being compared with INR-adjusted warfarin on the safety of treatment. Major and clinically relevant nonmajor bleeding are the safety outcomes. About 2000 patients are planned to be included in the study (ClinicalTrials.gov identifier NCT00504556).

\section{PRT054021}

PRT054021 has a $\mathrm{K}_{\mathrm{i}}$ for FXa of $0.117 \mathrm{nM}$ and demonstrated antithrombotic activity in animal models. ${ }^{46} \mathrm{~A}$ multicenter, randomized, phase II study has recently been initiated to evaluate the safety and efficacy of PRT054021 $40 \mathrm{mg}$ twice daily and $15 \mathrm{mg}$ twice daily compared with enoxaparin $30 \mathrm{mg}$ twice daily for the prevention of VTE in $\sim 200$ patients undergoing TKR (ClinicalTrials.gov identifier NCT00375609).

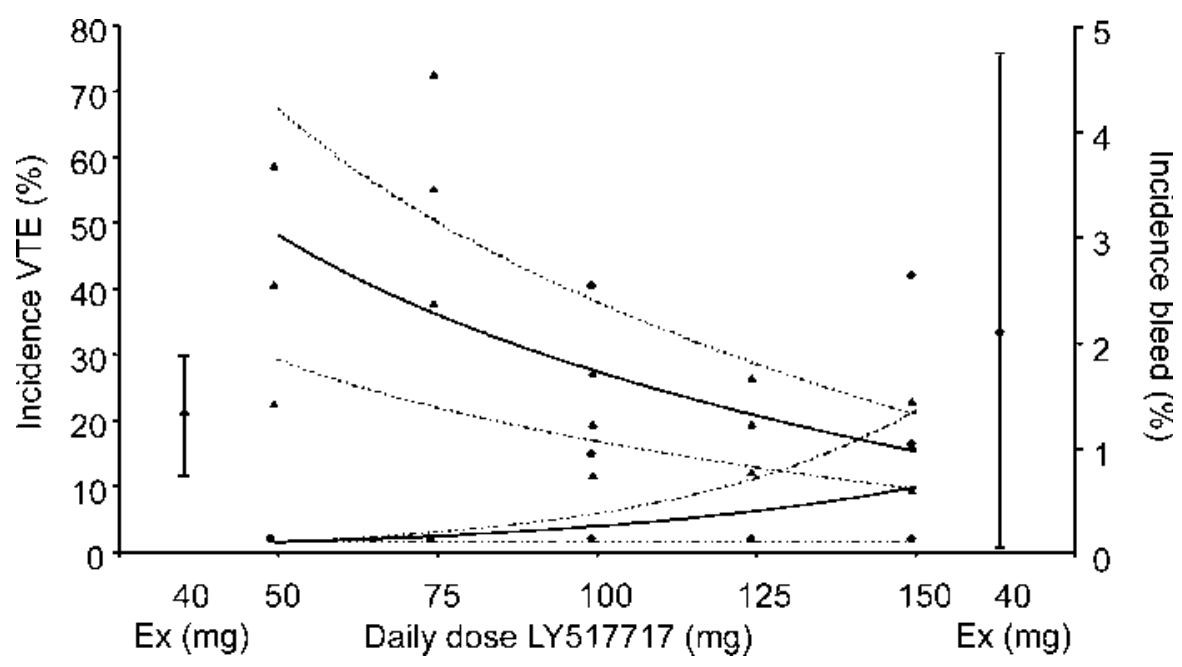

Figure 8 Dose-response relationships between LY157717 and the incidences of VTE and bleeding. The lines are the mean dose-response curves for LY157717 for the daily doses. The mean incidences of VTE (left y-axis) and of bleeding (right y-axis) are solid lines; the dotted lines represent the $95 \% \mathrm{Cl}$ for VTE and the bleeding. The incidences of VTE and of bleeding during treatment with enoxaparin $40 \mathrm{mg}$ daily are shown on the right and left sides of the doses of LY1517717, respectively. Ex, enoxaparin. 


\section{THROMBIN INHIBITORS}

Thrombin is another target for selective oral thrombin inhibitors. Thrombin not only converts fibrinogen to fibrin but also activates FXIII. Thrombin renders fibrin resistant to fibrinolysis by inhibiting crosslinking of fibrin and cross-linking of $\alpha 2$-antiplasmin to fibrin. Prothrombotic roles of thrombin are mediated through platelet activation, positive feedback on coagulation factors V, VIII, and XI, and antithrombotic roles in the activation of protein $\mathrm{C}$ and thrombin activatable fibrinolysis inhibitor. Thrombin is the principal activator of platelets at sites of injury through its interaction with platelet protease activated receptor (PAR)-1 and PAR-4. ${ }^{47}$

\section{Hirudins}

Direct thrombin inhibitors inactivate fibrin-bound thrombin in addition to fluid-phase thrombin. Consequently, they may attenuate thrombus accretion more effectively. Further, direct thrombin inhibitors produce a more predictable anticoagulant effect than does heparin because they do not bind to plasma proteins and are not neutralized by platelet factor 4 (PF4) and highmolecular-weight multimers of von Willebrand factor generated at sites of vascular injury. ${ }^{48}$

Three parenteral direct thrombin inhibitors have been licensed for some indications. Hirudin and argatroban are approved for the treatment of heparin-induced thrombocytopenia, whereas bivalirudin is licensed as an alternative to heparin in patients undergoing percutaneous coronary interventions. ${ }^{49}$

\section{Ximelagatran}

The first orally available direct thrombin inhibitor ximelagatran is a dipeptide mimetic of the region of fibrinopeptide A that interacts with thrombin's active site. $^{50}$

Ximelagatran has been evaluated and shown to have efficacy in several settings, including thromboprophylaxis in high-risk orthopedic patients, treatment of venous thromboembolism, prevention of cardioembolic events in patients with nonvalvular AF, and prevention of recurrent ischemia in patients with recent myocardial infarction. Recurrent thromboembolic events were also observed in patients with acute VTE after termination of treatment with ximelagatran. ${ }^{51}$

The ALT increased in all long-term studies with melagatran in $10 \%$ of patients. In $\sim 2 \%$ of patients, ALT increased more than threefold the ULN. ${ }^{52}$ The time course of ALT and in addition of aspartate aminotransferase (AST) were analyzed. A less frequent and lower increase of AST values compared with ALT values indicates a nontoxic effect of ximelagatran on liver cells. ${ }^{53}$
A New Drug Application (NDA) was filed in the United States for ximelagatran for the indications of DVT prophylaxis after total knee replacement, secondary prophylaxis of VTE after initial anticoagulant therapy, and stroke prevention in AF. Because of concerns about hepatotoxicity, the FDA denied approval of ximelagatran in $2004 .^{54}$

\section{Dabigatran}

Dabigatran etexilate is an orally available prodrug that is converted to dabigatran, the active moiety. It is a potent, competitive, and reversible direct inhibitor of thrombin. Peak dabigatran plasma concentrations occur 0.5 to 2 hours after oral administration, resulting in a rapid onset of action. There is a biexponential distribution phase with a terminal half-life of 12 to 17 hours. As much as $80 \%$ of the drug is excreted unchanged by the kidneys. The average absolute bioavailability of dabigatran is $6.5 \% .^{55}$

In a multicenter, parallel-group, double-blind study, 1973 patients undergoing total hip or knee replacement were randomized to 6 to 10 days of oral dabigatran (50 or $150 \mathrm{mg}$ twice daily, $300 \mathrm{mg}$ once daily, $225 \mathrm{mg}$ twice daily), starting 1 to 4 hours after surgery, or to subcutaneous enoxaparin (40 $\mathrm{mg}$ once daily) starting 12 hours prior to surgery. VTE occurred in $28.5 \%, 17.4 \%, 16.6 \%, 13.1 \%$, and $24 \%$ of patients assigned to dabigatran 50 or $150 \mathrm{mg}$ twice daily, $300 \mathrm{mg}$ once daily, $225 \mathrm{mg}$ twice daily, and enoxaparin, respectively. A significant dose-dependent decrease of VTE occurred with increasing doses of dabigatran $(p<0.0001)$. Compared with enoxaparin, VTE was significantly lower in patients receiving $150 \mathrm{mg}$ twice daily $(p=0.04), 300 \mathrm{mg}$ once daily $(p=0.02)$, and $225 \mathrm{mg}$ twice daily $(p=0.0007)$. Compared with enoxaparin, major bleeding was significantly lower with $50 \mathrm{mg}$ twice daily ( $0.3 \%$ vs. $2.0 \%, p=0.047)$ but elevated with higher doses with the $300 \mathrm{mg}$ once-daily dose $(4.7 \%, p=0.051)$ (Fig. 9). ${ }^{56}$

\section{TREATMENT AND PROLONGED PROPHYLAXIS OF ACUTE VTE}

The treatment of acute DVT and PE is being investigated in a phase III randomized, double-blind, parallel-group study of the efficacy and safety of oral dabigatran (150 mg twice daily) compared with warfarin (INR 2.0 to 3.0) for 6-month treatment of acute symptomatic VTE after initial treatment (5 to 10 days) with a parenteral anticoagulant approved for this indication (RE-COVER study; ClinicalTrials.gov identifier NCT00291330).

The prolonged prophylaxis of recurrent VTE is being studied in a phase III randomized, double-blind, double-dummy clinical trial comparing the efficacy and safety of $150 \mathrm{mg}$ dabigatran etexilate twice daily 


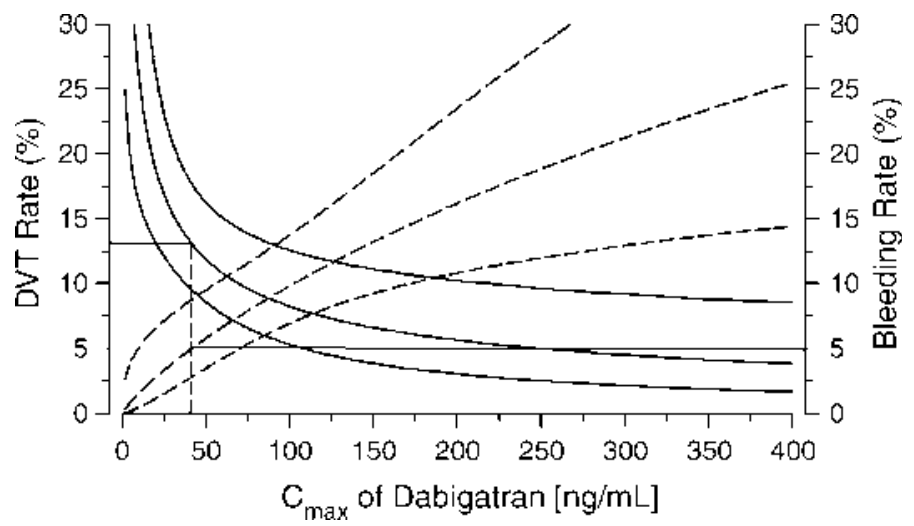

Figure 9 Logistic regression analysis of $C_{\max }$ on day 1 versus DVT rate (solid curves) and clinically relevant (major plus clinical significant) bleeding (dashed curves). The median percentage of events and corresponding $95 \% \mathrm{Cl}$ are demonstrated. A $5 \%$ rate of clinically relevant bleeding (solid horizontal line) corresponds with a predicted dabigatran plasma concentration of $40 \mathrm{ng} / \mathrm{mL}$ and a DVT rate of $13 \%$.

to INR-adjusted warfarin after an initial anticoagulant therapy of 3 to 12 months for an additional 18 months (REMEDY study; ClinicalTrials.gov identifier NCT00329238).

In a second study, the prolonged prophylaxis of recurrent VTE is being studied in a phase III randomized, double-blind, clinical trial comparing the efficacy and safety of $150 \mathrm{mg}$ dabigatran etexilate twice daily versus placebo after an initial anticoagulant therapy of 6 to 18 months for an additional 18 months. The primary end points are actively confirmed symptoms of recurrent DVT or PE. About 2000 patients will be required to demonstrate the superiority of dabigatran (RESONATE study; ClinicalTrials.gov identifier NCT00558259).

\section{OTHER INDICATIONS}

In the PETRO trial, 3 doses of dabigatran (50, 150, and $300 \mathrm{mg}$ twice daily) were combined with no aspirin or $81 \mathrm{mg}$ or $325 \mathrm{mg}$ aspirin once daily in patients with AF. Patients received warfarin alone (INR 2 to 3 ) in the comparator group. The trial was double-blind with respect to dabigatran dose but open-label for concomitant aspirin treatment and for randomization between dabigatran and warfarin groups. Randomization was stratified in the ratio 6:9:9:4 (50, 150, and $300 \mathrm{mg}$ dabigatran, and warfarin, respectively) The primary outcome was the frequency of bleeding events.

Major bleeding events were limited to the group treated with $300 \mathrm{mg}$ dabigatran twice daily plus aspirin (4 of 64). The rate was statistically different compared with the group treated with dabigatran $300 \mathrm{mg}$ twice daily without aspirin ( 0 of $105, p=0.02$ ). There was a significant difference in major plus clinically relevant bleeding episodes (11 of 64 vs. 6 of 105, $p=0.03$ ) and total bleeding episodes (25 of 64 vs. 14 of 105, $p=0.0003$ ) between $300 \mathrm{mg}$ dabigatran twice daily plus aspirin and $300 \mathrm{mg}$ dabigatran twice daily without aspirin. The frequency of bleeding in the group treated with $50 \mathrm{mg}$ dabigatran twice daily was significantly lower than that in the warfarin group: 7 of 107 versus 12 of $70(p=0.044)$. When the doses of dabigatran were compared with each other, irrespective of aspirin assignment, there were differences in total bleeding episodes in the $300 \mathrm{mg}$ twice-daily and $150 \mathrm{mg}$ twice-daily groups versus the $50 \mathrm{mg}$ twice-daily group (37 of 169 and 30 of 169 vs. 7 of $107, p=0.0002$ and $p=0.01$, respectively).

There was a $0.9 \%$ incidence of increased aminotransferase levels $>3$ times the ULN in dabigatrantreated patients (4 of 432). Adverse events were more frequent in the dabigatran groups than in the warfarintreated patients. Because of liver function abnormalities associated with ximelagatran, the current study had an extensive surveillance of liver function. Only $0.9 \%$ of patients had increased levels of ALT or AST $>3$ times the ULN. No patient had a drug-related increase in bilirubin $>2$ times the ULN within 30 days after an aminotransferase level increase $>3$ times the ULN. However, the duration of the study was only 12 weeks. ${ }^{57}$ The phase II clinical trial investigating dabigatran in patients with chronic AF has been extended for 2 years to investigate the safety and efficacy of $\sim 360$ patients who have previously been treated in the Pedro study (Pedro-Ex; ClinicalTrials.gov identifier NCT00157248).

In a phase III trial, a randomized evaluation of long-term anticoagulant therapy (RE-LY) compares the efficacy and safety of two blinded doses of dabigatran with open-label warfarin for the prevention of stroke and systemic embolism in patients with nonvalvular AF. It is a prospective, multicenter, randomized, open-label, controlled parallel group, noninferiority trial. The primary end point is to demonstrate that the efficacy and safety of two blinded doses of dabigatran are noninferior to warfarin treatment for the prevention of stroke and systemic embolism. More than 16,000 patients were randomized (www.ClinicalTrials.gov identifier NCT00262600). 


\section{CONCLUSION}

The work of Eberhard Mammen on the development of new anticoagulants is continuing as the new anticoagulants may succeed in demonstrating improved efficacy and safety potentials compared with those of vitamin $\mathrm{K}$ antagonists and heparins. The synthetic, specific small molecules open the possibility to treat patients without monitoring and dose adjustment. Dose-ranging studies demonstrated a broader therapeutic range. A prolonged prevention and treatment of thromboembolic diseases, anticoagulation of older patients, the development of new indications for antithrombotic therapies, and the combination with platelet inhibitors are attractive perspectives for the new anticoagulants.

\section{REFERENCES}

1. Beller FK, Mammen E. Studies on a third plasma factor in thromboplastin formation. Klin Wochenschr 1955;33: 155-156

2. Nieth H, Mammen E, Gross R. Heparinization of blood in extracorporeal hemodialysis. Klin Wochenschr 1958;36: 372-376

3. Troy S, Fruncillo R, Ozawa T, Mammen E, Holloway S, Chiang $\mathrm{S}$. The dose proportionality of the pharmacokinetics of ardeparin, a low molecular weight heparin, in healthy volunteers. J Clin Pharmacol 1995;35:1194-1199

4. Mammen EF. Why low molecular weight heparin? Semin Thromb Hemost 1990;16(Suppl):1-4

5. Mammen EF, Arcelus J, Messmore H, Altman R, Nurmohamed M, Eldor A. Clinical differentiation of low molecular weight heparins. Semin Thromb Hemost 1999;25(Suppl 3): 135-144

6. Harenberg J, Casu B. Glycosaminoglycans I. Semin Thromb Hemost 1994;20:133-222

7. Harenberg J, Casu B. Glycosaminoglycans: anticoagulant and nonanticoagulant actions. Semin Thromb Hemost 2002;28: 325-402

8. Harenberg J, Casu B. New anticoagulants. Semin Thromb Hemost 2007;33:449-562

9. Mammen EF. Preface. Glycosaminoglycans: anticoagulant and nonanticoagulant actions. Semin Thromb Hemost 2002; 28:323-324

10. Bates SM, Weitz JI. The status of new anticoagulants. Br J Haematol 2006;134:3-19

11. Hirsh J, O’Donnell M, Eikelboom JW. Beyond unfractionated heparin and warfarin: current and future advances. Circulation 2007;116:552-560

12. Eikelboom JW, Weitz JI. A replacement for warfarin. The search continues. Circulation 2007;116:131-133

13. Saiah E, Soares C. Small molecule coagulation cascade inhibitors in the clinic. Curr Top Med Chem 2005;5:16771695

14. Bauer KA. New anticoagulants. Hematology (Am Soc Hematol Educ Program) 2006:450-456

15. Turpie AGG. Oral, direct factor Xa Inhibitors in development for the prevention and treatment of thromboembolic diseases. Arterioscler Thromb Vasc Biol 2007;27:12381247
16. $\mathrm{Ma} \mathrm{Q}_{2}$ Fareed J. Idraparinux sodium. Sanofi-Aventis. IDrugs 2004;7:1028-1034

17. Herbert JM, Herault JP, Bernat A, et al. Biochemical and pharmacological properties of SANORG 34006, a potent and long-acting pentasaccharide. Blood 1998;91:4197-4205

18. Bijsterveld NR, Vink R, Van Arken BE, et al. Recombinant factor VIIa reverses the anticoagulant effect of the longacting pentasaccharide idraparinux in healthy volunteers. Br J Haematol 2004;124:653-658

19. The van Gogh Investigators. Idraparinux versus standard therapy for venous thromboembolic disease. N Engl J Med 2007;357:1094-1104

20. The van Gogh Investigators. Extended prophylaxis of venous thromboembolism with idraparinux. N Engl J Med 2007; 357:1105-1112

21. Amadeus InvestigatorsBousser MG, Bouthier J, Bü;ller HR, et al. Comparison of idraparinux with vitamin $\mathrm{K}$ antagonists for prevention of thromboembolism in patients with atrial fibrillation: a randomised, open-label, non-inferiority trial. Lancet 2008;371:315-321

22. Harenberg J, Joerg I, Vukojevic Y, Weiss C, Mikus G. Anticoagulant effects of idraparinux after termination of therapy for prevention of recurrent venous thromboembolism: observations from the van Gogh trials. Eur J Clin Pharmacol 2008;64:555-563

23. Harenberg J, Weiss C, Mikus G, Joerg I, Vukojevic Y. Long elimination half life of idraparinux after termination of therapy explains bleeding in the van Gogh trials. J Thromb Haemost 2008;6:890-892

24. Savi P, Herault JP, Duchaussoy P, et al. Reversible biotinylated oligosaccharides, a new approch for a better management of the anticoagulant therapy. J Thromb Haemost 2008;6:1697-1706

25. Lassen MR, Dahl OE, Mismetti P, Destrèe D. AV5026, a new anticoagulant for prevention of venous thromboembolism in total knee replacement surgery - TREK: a dose ranging study. Blood 2007;110: Abstract 311

26. Paccaly A, Frick A, Rohatagi S, et al. Pharmacokinetics of otamixaban, a direct factor Xa inhibitor, in healthy male subjects: pharmacokinetic model development for phase $2 / 3$ simulation of exposure. J Clin Pharmacol 2006;46:37-44

27. Cohen M, Deepak L, Bhatt DL, et al; on behalf of the SEPIA-PCI Trial Investigators. Randomized, double-blind, dose-ranging study of otamixaban, a novel, parenteral, shortacting direct factor xa inhibitor, in percutaneous coronary intervention: the SEPIA-PCI Trial. Circulation 2007;115: 2642-2651

28. Rezaie AR. DX-9065a inhibition of factor Xa and the prothrombinase complex: mechanism of inhibition and comparison with therapeutic heparins. Thromb Haemost 2003;89:112-121

29. Alexander JH, Yang $\mathrm{H}$, Becker RC, et al; on behalf of the XANADU-ACS Investigators. First experience with direct, selective factor $\mathrm{Xa}$ inhibition in patients with non-STelevation acute coronary syndromes: results of the XANADU-ACS trial. J Thromb Haemost 2005;3:439-447

30. Kubitza $\mathrm{D}, \mathrm{Haas} \mathrm{S}$. Novel factor Xa inhibitors for prevention and treatment of thromboembolic diseases. Expert Opin Investig Drugs 2006;15:843-855

31. Eriksson BI, Lars C, Borris LC, et al; for the ODIXa-HIP Study Investigators. A once-daily, oral, direct factor Xa inhibitor, rivaroxaban (BAY 59-7939), for thromboprophylaxis after total hip replacement. Circulation 2006;114:2374-2381 
32. Lassen MR, Ageno W, Borris LC, et al; for the RECORDS 3 Investigators. Rivaroxaban versus enoxaparin for thromboprophylaxis after total knee arthroplasty. N Engl J Med 2008; 358:2276-2286

33. Kakkar AK, Brenner B, Dahl OE, et al. Extended thromboprophylaxis with rivaroxaban compared with shortterm thromboprophylaxis with enoxaparin after total hip arthroplasty: the RECORD2. Blood 2007;110: Abstract 307

34. Eriksson BI, Borris LC, Friedman RJ, et al; for the RECORD 1 Study Group. Rivaroxaban versus enoxaparin for thromboprophylaxis after total hip arthroplasty: The RECORD1. N Engl J Med 2008;358:2765-2775

35. Mueck W, Agnelli G, Buller H. Rivaroxaban has predictable pharmacokinetics (PK) and pharmacodynamics (PD) when given once or twice daily for the treatment of acute, proximal deep vein thrombosis (DVT). Blood 2007;110:Abstract 1880

36. Agnelli G, Gallus A, Goldhaber SZ, et al; for the ODIXaDVT Study Investigators. Treatment of proximal deep-vein thrombosis with the oral direct Factor Xa inhibitor rivaroxaban (BAY 59-7939) The ODIXa-DVT Study. Circulation 2007;116: 180-187

37. Buller HR, Lensing AW, Prins MH, et al. Einstein-DVT Dose-Ranging Study investigators. A dose-ranging study evaluating once-daily oral administration of the factor $\mathrm{Xa}$ inhibitor rivaroxaban in the treatment of patients with acute symptomatic deep vein thrombosis: the Einstein-DVT Dose-Ranging Study. Blood 2008;112: 2242-2247

38. Pinto DJ, Orwat MJ, Koch S, et al. Discovery of 1-(4methoxyphenyl)-7-oxo-6-(4-(2-oxopiperidin-1-yl)phenyl)4,5,6,7-tetrahydro- $1 \mathrm{H}$-pyrazolo[3,4-c]pyridine-3-carboxamide (apixaban, BMS-562247), a highly potent, selective, efficacious, and orally bioavailable inhibitor of blood coagulation factor Xa. J Med Chem 2007;50:5339-5356

39. Lassen MR, Davidson BL, Gallus A, Pineo G, Ansell J, Deitchman D. The efficacy and safety of apixaban, an oral, direct factor Xa inhibitor, as thromboprophylaxis in patients following total knee replacement. J Thromb Haemost 2007; 5:2368-2375

40. Botticelli InvestigatorsWriting CommitteeBuller $H$, Deitchman D, Prins M, Segers A. Efficacy and safety of the oral direct factor $\mathrm{Xa}$ inhibitor apixaban for symptomatic deep vein thrombosis. The Botticelli DVT dose-ranging study. J Thromb Haemost 2008;6:1313-1318

41. Iwatsuki Y, Shigenaga T, Moritani Y, et al. Biochemical and pharmacological profiles of YM150, an oral direct factor Xa inhibitor. Blood 2006;108:Abstract 911

42. Eriksson BI, Turpie AGG, Lassen ML, et al; on behalf of The Onyx Study Group. A dose escalation study of YM150, an oral direct factor $\mathrm{Xa}$ inhibitor, in the prevention of venous thromboembolism in elective primary hip replacement surgery. J Thromb Haemost 2007;5:1660-1665
43. Eriksson BI, Turpie AGG, Lassen MR, et al. Once daily YM150, an oral direct factor Xa inhibitor, for prevention of venous thromboembolism in patients undergoing elective primary hip relpacement. Blood 2007;110:Abstract 309

44. Eriksson BI, Quinlan DJ. Oral anticoagulants in development: focus on thromboprophylaxis in patients undergoing orthopaedic surgery. Drugs 2006;66:1411-1429

45. Agnelli G, Haas SK, Krueger KA, et al. A phase II study of the safety and efficacy of a novel oral FXa inhibitor (LY517717) for the prevention of venous thromboembolism following TKR or THR. J Thromb Haemost 2007;5:746-753

46. Abe K, Siu G, Edwards S, et al. Animal models of thrombosis help predict the human therapeutic concentration of PRT54021, a potent oral factor Xa inhibitor. Blood 2006;108: Abstract 901

47. Linkins LA, Weitz JI. Pharmacology and clinical potential of direct thrombin inhibitors. Curr Pharm Des 2005;11: 3877-3884

48. Weitz JI. Factor Xa or thrombin: is thrombin a better target? J Thromb Haemost 2007;5(Suppl 1):65-67

49. Weitz JI, Buller HR. Direct thrombin inhibitors in acute coronary syndromes: present and future. Circulation 2002; 105: 1004-1011

50. Gustafsson D, Nystrom J, Carlsson S, et al. The direct thrombin inhibitor melagatran and its oral prodrug $\mathrm{H} 376 / 95$ : intestinal absorption properties, biochemical and pharmacodynamic effects. Thromb Res 2001;101:171-181

51. Harenberg J, Jörg I, Weiss C. Incidence of recurrent venous thromboembolism of patients after termination of treatment with ximelagatran. Eur J Clin Pharmacol 2006;62:173-177

52. Gurewich V. Ximelagatran-promises and concerns. JAMA 2005;293:736-739

53. Harenberg J, Jörg I, Weiss C. Observations of alanine aminotransferase and aspartate aminotransferase in THRIVE studies treated orally with ximelagatran. Int J Toxicol 2006;25: 165-169

54. Lee WM, Larrey D, Olsson R, et al. Hepatic findings in long-term clinical trials of ximelagatran. Drug Saf 2005; 28:351-370

55. Stangier J, Rathgen K, Staehle H, Gansser D, Roth W. The pharmacokinetics, pharmacodynamics and tolerability of dabigatran etexilate, a new oral direct thrombin inhibitor, in healthy male subjects. Br J Clin Pharmacol 2007;64:292-303

56. Eriksson BI, Dahl OE, Buller HR, et al. A new oral direct thrombin inhibitor, dabigatran etexilate, compared with enoxaparin for prevention of thromboembolic events following total hip or knee replacement: the BISTRO II randomized trial. J Thromb Haemost 2005;3:103-111

57. Ezekowitz MD, Reilly PA, Nehmiz G, et al. Dabigatran with or without concomitant aspirin compared with warfarin alone in patients with nonvalvular atrial fibrillation (PETRO study). Am J Cardiol 2007;100:1419-1426 